\title{
THE RELATIONSHIP OF DOCUMENT AND QUANTITATIVE LITERACY WITH LEARNING STYLES AND SELECTED PERSONAL VARIABLES FOR AVIATION UNIVERSITY STUDENTS
}

\author{
Royce Ann Martin \\ Bowling Green State University
}

\begin{abstract}
The purpose of this study was to determine the extent to which university student scores on a researcher-constructed quantitative and document literacy test were associated with learning style, program of study, cumulative grade point average, and year in school. Instruments used for the study were the 35 question Aviation Documents Delineator (ADD) and the Learning Type Measure (LTM). Data collected were analyzed using a step-wise multiple regression analysis technique. The ADD was designed to identify a student's ability and preference for interpreting and using graphic or tabular data. Study results reveal that year in school and GPA were significant predictors of literacy scores on the ADD while learning style and the student's program of study were not.
\end{abstract}

\section{INTRODUCTION}

The department of aerospace technology at Indiana State University offers two programs of study: aerospace administration and professional pilot. Students' success in the professional pilot and aerospace administration programs depends upon their ability to read and interpret documents. The curriculum content of the professional pilot and aerospace administration programs involves the use of airplane performance tables and graphs, thematic weather maps, sectional navigation charts, instrument reference maps, weight and balance tables and graphs, take off and landing graphs, etc. In addition, both curricular areas include concepts involving airport operations, planning, and management which require interpretation of financial reports, break-even analysis graphs, aviation industry forecast tables and graphs, and economic ordering quantity graphs. Learners are also expected to be able to calculate throughput and practical capacity of airports and interpret probability distributions of aircraft delays. The ability to use written documents and to apply mathematical operations to such documents constitutes an important part of the aerospace technology's curriculum.

The ability to extract relevant information from tables, graphs, and maps (document literacy) and to perform mathematical calculations related to print embedded in tables and graphs (quantitative literacy) is useful to the aviation major for the following reasons:

1. Pilots are required by Federal Aviation 
Regulations (FARs) 91, 121, and 135 to know the performance characteristics of the aircraft they fly. Aircraft manufacturers display performance data in two primary formats (Taylor, 1991, p. 67). Some present the information in graphic form; others primarily utilize tables to depict relevant aircraft performance data. Additionally, preflight planning activities required by the pilot require interpretation of tables and graphs.

2. Ability to interpolate is often required in exercising flight decisions because not all the values for the infinitely possible combinations of varying conditions that exist in aviation industry tables and graphs are listed.

3. Pilot safety depends upon the pilot's ability to read and interpret performance tables and graphs. Many accidents have resulted because of pilots' failures to understand the effect of the various flight conditions on airplane performance. Misinterpretation of essential airplane weight and balance data has also contributed to hazardous flight operations.

4. Students' difficulties with quantitative literacy are as much a problem of being able to analyze and interpret the relationships of the related data provided in the document as they are a problem with simple arithmetic calculations. Success at arithmetic operations on the job was often associated with the ability to appropriately extrapolate needed information from documents (Mosenthal \& Kirsch, 1993).

5. Competence in utilizing both graphic and tabular document formats with ease may help contribute to an individual's success (Quilty, 1996). Guthrie, Seifert, and Kirsch (1986) noted that the use of documents played a major role in the daily lives of Americans on and off the job; regardless of occupational type, gender, or education, subjects reported reading documents more than other types of material. Mosenthal and Kirsch (1989, p. 58) noted, "In elementary schools, we 'learned to read' using narratives. In secondary and post secondary schools we 'read to learn' using exposition. But in life beyond school, we 'read to do' using documents."

This author has been teaching aviation management and professional pilot ground school courses for the past ten years. During this time, it was observed that regardless of the aviation students' major program of study, those who appeared to do well at interpreting and utilizing documents in graphic format seemed to possess learning style preferences that were distinctly different from those aviation students who were more skilled at utilizing documents presented in a tabular format. It was also noted by this researcher that some of the same students who were more competent at extracting relevant information from graphs appeared to be more skillful at performing mathematical calculations related to print embedded in tables and graphs. Desiring to learn more about how to assist the students who were experiencing difficulty with tables and graphs and with math calculations related to such documents, the author designed the Aviation Documents Delineator (ADD). Using the ADD, the present study was conducted to determine if students had greater difficulty with interpreting information presented in graphs versus information presented in a table format, to assess the students' document and 
quantitative literacy, and sought to answer the following questions: Are grade point average (GPA), year in school, and program of study associated with students' abilities to read and interpret documents, graphs, tables, and maps, or with their quantitative skills in using these materials? Additionally, the study investigated whether skill in utilizing the documents was associated with an individual's learning style, as defined by the Learning Type Measure (LTM), developed by Bernice McCarthy (1995).

\section{BACKGROUND}

Direct measurement of literacy skills using the refined categories of document and quantitative literacy are relatively new (Barton, 1994). In a review of the literature regarding locating information from documents, Sticht and Armstrong (1994) reported that the first reference to the terms document and quantitative literacy initially appeared in a 1986 NAEP study of young adults in the U.S. Miller (1982) observed that a lot of the occupational-related reading tended to involve documents, was more complex, and demanded more inferential thinking and problem solving. Miller also contended that a challenge to educators in post secondary education would be to help the students bridge the gap in skills using documents.

Guthrie and Mosenthal (1986, p. 284) observed that "despite its apparent pervasiveness, locating information is rarely taught either in textbooks or by teachers." They reiterated Armbruster and Gudbrandsen's research findings (1986) which indicated that though students were expected to use information-seeking skills, they were given little guidance or instruction on how to locate information embedded in documents. In Mosenthal and Kirsch's (1989) study on document literacy, they concluded that teachers did not often examine how the more adept students navigated the documents differently from those that were more disadvantaged with documents. Using the ADD, this author sought to obtain insight into aviation students' skills at using documents and into the various factors that enable some students to perform better with documents than other students.

In the ADD the two constructs, document and quantitative literacy, were treated as two separate but related skills. Various researchers have reported that the strategies involved with document and quantitative literacy were cognitively different from the strategies used in narrative and expository forms of reading (Kirsch \& Mosenthal, 1990; Sheehan \& Mislevy, 1990). Researchers addressed the need for considering both document and quantitative literacy as they pertain to individuals' lives on the job (Mikulecky, 1985; Phillipi, 1988). The need to examine more fully the ergonomic issues of document and quantitative literacy was also suggested by the military in the 1970's, (Sticht \& Armstrong, 1994), by industry (Chisman, 1990), by the FAA (General Aviation Manufacturers Association [GAMA], 1975), and by other governmental agencies (Mosenthal \& Kirsch, 1993). In their studies, each of the above agencies pursued strategies to re-design and simplify documents to facilitate improved document literacy.

The importance of distinguishing the specific skills of document and quantitative literacy is currently supported by the growing attention given to assessment of document and quantitative literacy skills. Contemporary literacy definitions share an emphasis on document processing, computational skills, and problem solving within a particular document context. Support for future studies in quantitative 
literacy were made by Edward Tufte (1986) in his book, The Visual Display of Quantitative Information, where he emphasized that quantitative literacy is an important construct that needs further investigation. Corroborative findings were suggested by Head and Moore (1991). Their investigation focused on graphic format and interpretation of numerical data by students who were identified by their cognitive type (field dependent and field independent). Although they only found a weak relationship between the cognitive types of field dependence/independence and graphical forms, they indicated further investigations into the significance of cognitive type and document literacy skills might be warranted. Lawrence (1988) also examined learning styles as it related to individuals learning mathematics. He concluded that an adult's learning style affected his/her approach to learning mathematics and that knowledge of a student's learning style was useful in planning successful teaching strategies for individual students who exhibited difficulties with learning specific tasks or concepts in math.

Quilty's study (1996) also supported the existence of a relationship between learning styles and interpretation of various graphic formats of quantitative data. In his study involving aviation students, corporate pilots, and airline pilots, he suggested that individuals having a cognitive bias for sequential learning were more adept at using tables than graphs, whereas those with a cognitive bias for relational patterns interpret data better that is presented in a graphic format. His data supported the belief that in order for aviation students to succeed, instructional techniques used in the classroom should take into consideration the various cognitive preferences of each of the students. Because document and quantitative skills are so widely used in aviation preparatory programs and in the aviation profession, the question of how to improve document and quantitative literacy has relevance for improved flight safety of pilots and for improved efficiency of aerospace administrators on the job. Aviation industry preparatory programs may be improved if instruction is tailored to the needs of the students.

The concept of learning styles builds upon the individual approach to learning that Taba (1962), Bloom (1976), and Goodlad (1984) advocated. Quilty's study (1999) echoed the notion that in curriculum planning, if equality of opportunity for students' learning is to be realized, educators must first ask which individual differences of the learners were significant. Additional studies by Dunn and Dunn (1993) and McCarthy and St. Germain (1996) focused on accommodation of students' learning styles to improve students' learning and grade point average. Furthermore, Sternberg (1990) and Quilty (1996) both warned that because the educational setting and the different occupations reward distinctly different cognitive styles, potential capable workers whose chosen careers do not suit their preferred cognitive style may be unnecessarily screened out of the future candidate pool.

Over the years, many cognitive/ learning styles models for understanding these differences have been developed. Each of the models provides explanations for the many alternative ways in which individuals perceived, processed, and approached problem solving. For assessing learning styles in the present study, this author chose to use the Learning Type Measure (LTM) based upon research conducted by Bernice McCarthy (1996). Unlike many of the learning style instruments currently on the market, it is relatively easy for the subjects to comprehend, easy to administer, and 
relatively short in length. Another important aspect of her instrument is that although it builds upon the theoretical work done by Jung and Kolb, her research differs distinctly from previous personality type research in that she provided a practical application for using the information for designing curriculum.

In developing the LTM, McCarthy noted that there were four primary learning styles that could be used to categorize learners' comfortable way of knowing about their world. She explained that individuals had distinctive and consistent ways of interacting with the world; these characteristic differences she labeled learning styles. McCarthy based her assessment of cognitive type upon two basic dimensions of learning that represented the learner's typical mode of perceiving, thinking, problem solving and organizing information: perception and information processing. She described two ways of perceiving and the two ways of processing information, which resulted in a fourquadrant model of learning styles. McCarthy explained that the resulting four learning style types actually represented a continuum between opposite extremes of the two dimensions because each individual's innate preferences for one side or the other along the continuum helped to characterize one's learning type. At one end of the dimension of perception were individuals who perceived through concrete experiences; at the opposite end were individuals who perceived through abstract conceptualization.

\section{METHODOLOGY}

\section{Participants}

This study investigated the relationship of document and quanti-tative literacy with learning styles and selected personal variables for aerospace technology students at Indiana State University. The sample was a non-random, intact group that included 143 aerospace technology department students who were present in class on both days of testing. The demographic make-up of the sample consisted of 15 females and 128 males. The sample included 46 freshmen, 25 sophomores, 32 juniors, and 40 seniors. Ninety-four of the students were declared professional pilot majors, 32 were aerospace administration majors, 10 were double majors (professional pilot and aerospace administration), and 8 were majoring in programs outside of the school of technology (music education, economics, social studies education, criminology, computers science, physics, and mathematics).

\section{Survey Instruments}

The Aviation Documents Delineator (ADD)

Document and quantitative literacy were assessed using the Aviation Documents Delineator (ADD). The ADD required subjects to complete document literacy tasks which included the ability to (a) locate information embedded in the documents, (b) integrate, interpret, and compare information across the different segments of the documents, and (c) demonstrate understanding of the documents. For quantitative literacy tasks, subjects were additionally required to (a) demonstrate logical and analytical skills in interpreting tables, graphs, and maps, using single and/or sequential multiple arithmetic operations, and to (b) interpolate or interpret scaled relationships on tables, graphs, or maps.

The tasks in the ADD included (a) 
marking a point on the document that represented the answer, (b) locating, interpreting, and describing specific data displayed in the document, (c) determining data for a specified point on the table through interpolation, (d) comparing data for a string of variables representing one aspect of aircraft performance to another string of variables representing a different aspect of aircraft performance, (e) describing how data in a particular column of a table were calculated, (f) comparing information in two separate documents, $(\mathrm{g})$ using information in the documents to make predictions about future trends regarding specific variables displayed in the documents, (h) interpreting the documents to make decisions regarding emergency situations, (i) calculating different percentages for data given, and (j) performing single and/or sequential mathematical operations on a specified set of data. All items reflected tasks that were associated with the aviation industry.

The ADD was field tested with two groups of students: aviation students at the University of Illinois and non-aviation students at Indiana State University. An odd-even reliability test and an item analysis were conducted on the field-tested instrument. The instrument was subsequently revised using the information obtained from preliminary administration of the instrument. The answer guide was reconstructed and checked for accuracy by a five-member test panel consisting of three pilots and two professionals working in aerospace administration. The internal reliability of the final form of the instrument was also checked by the same test panel. Reliability of the ADD was further strengthened by administering the test on two separate test days and by having 3 separate 20-minute sections for comparison. In addition, using a pre-made form for analyzing the ADD, the content validity of the individual test items was examined by three experienced pilots and two local literacy program instructors. An odd-even reliability test was also used on the final administration of the instrument.

\section{The Learning Type Measure (LTM)}

The Learning Type Measure (LTM) was a fifteen item self-report instrument designed to delineate each student's preferred learning style into four principal types: imaginative, analytic, common sense, and dynamic (McCarthy, 1996). St. Germain, Lieberman, and Cohen (1995) investigated the reliability and validity of the Learning Type Measure (LTM) that was developed in 1993 by McCarthy. From Florida's Community college system, 106 students enrolled in Introduction to Education courses were selected. The LTM was used to assess their personality style at the beginning of the semester and six weeks into the semester. A Kappa test was applied to check for the agreement between the two tests. The authors concluded that the LTM was a reliable tool for assessing one's learning style preference.

Reliability of the Learning Type Measure was assessed using both an internal consistency and a test-retest procedure. Internal consistency was determined using the Cronbach alpha statistic which was found to be 0.86 . This statistic was judged to be well within acceptable internal consistency reliability measures which had an alpha between 0.80 and 0.90 . Test-retest reliability was also calculated and found to be 0.71 which was reported to indicate a "high level of stability" (St. Germain, 1996).

\section{HYPOTHESES}

The researcher advanced the following null hypotheses for use in this 
study:

$\mathrm{H}_{01}$ : Learning style, grade point average, year of study, and program of study, either step-wise or collectively, did not significantly predict document literacy as measured by a subtest score on the ADD when tested at the 0.05 level of significance.

$\mathrm{H}_{02}$ : Learning style, grade point average, year of study, and program of study, either step-wise or collectively, did not significantly predict quantitative literacy as measured by a subtest score on the ADD when tested at the 0.05 level of significance.

$\mathrm{H}_{03}$ : Learning style, GPA, year of study, and program of study, either stepwise or collectively, did not significantly predict document and quantitative literacy as measured by a global score for total literacy on the ADD when tested at the 0.05 level of significance.

\section{RESULTS AND ANALYSIS}

A split halves Spearman Brown Coefficient of correlation was calculated for the ADD. The value of " $r$ " was found to be .645. The Spearman Brown Prophesy formula for split halves reliability correction was applied with the formula: $[2 \times \mathrm{r}] \div[1+$ r] An application of this formula revealed a reliability of .78. The probability that this coefficient was different from zero was calculated to be 0.00 . The reliability of the ADD was therefore, statistically confirmed.

Results of the step-wise multiple linear regression statistical analysis for predicting document literacy, quanti-tative literacy, and total literacy scores that were measured by the ADD, were tabulated in Tables 1, 2, and 3. Table 1 reveals the extent that the four independent variables (year in school, GPA, program of study, and learning style) were used to predict the criterion variable of document literacy. Tables 2 and 3 represent the effect the same four predictor variables had on predicting quantitative and total literacy, respectively. The variance $\left(\mathrm{R}^{2}\right)$ in Tables 1, 2, and 3 reflects the proportion of the three dependent variables (document, quantitative, or total literacy, respectively) that was explained by the four predictor variables, as shown in each of the respective tables. The effect of the predictor variables on the students' document, quantitative, and total literacy, was shown in rank order of proportion of additional explained variance in the three respective tables. (i.e. in all three tables, year in school is shown first to reflect that variable as having the most significant effect on the respective dependent variables.) SPSS was used to run the data for the analysis, so Sig $T$ was used to determine if the independent variables were significantly related to the dependent variables. (i.e. where the Sig T is greater than the .05 alpha level, the predictor variable was considered to not have a significant effect on the dependent variable.)

Table 1 indicates that the predictor variables, year in school and GPA, were found to be significantly predictive of document literacy by the step-wise regression analysis. The combination of year in school with GPA accounted for 44 per cent of the explained variance in students' document literacy score. The magnitude of the $\mathrm{R}^{2}$ indicated that the predictor variables of year in school and GPA provided unique information about the criterion variable that was not provided by the other two variables in the equation. The significance of 0.00 for year in school and GPA, respectively, revealed a statistically significant predictive value for document literacy.

The document literacy score $\left(\mathrm{Y}_{\mathrm{i}}\right)$ was predicted by the following regression equation:

$\mathrm{Yi}=9.77+.20($ Year in school $)+.57$ (GPA). The size of the Sig $\mathrm{T}$ for the two independent variables of learning style and program of study indicate that the additional 
variance explained by those variables were so negligible that they were not significant for predicting document literacy scores. The hypothesis that learning style, GPA, program of study, and learning style either step-wise or collectively did not significantly predict document literacy as measured by a document literacy score on the ADD when treated at the 0.05 level of significance was rejected.

Table 2 shows year in school and GPA to be significantly predictive of quantitative literacy by the step-wise regression analysis. The combination of year in school and GPA accounted for 33 per cent of the explained variance in students' quantitative literacy score. The magnitude of the $\mathrm{R}^{2}$ indicated that the predictor variables of year in school and GPA provided unique information about the criterion variable, quantitative literacy that was not provided by the other two variables in the equation. The significance of 0.00 for year in school and for GPA revealed a statistically significant predictive value for quantitative literacy.

The quantitative literacy score $\left(\mathrm{Y}_{\mathfrak{j}}\right)$ was predicted by the regression equation: $\mathrm{Y}_{\mathrm{j}}=.68+.38($ Year in school $)+.33(\mathrm{GPA})$. The size of the Sig $\mathrm{T}$ for the other two independent variables indicate that the additional variance explained by those variables were so negligible that they were not significant for predicting quantitative literacy.

The hypothesis that learning style, GPA, year in school, and program of study, step-wise or collectively, did not significantly predict quantitative literacy as measured by a quantitative literacy score on the ADD when tested at the 0.05 level of significance was rejected. 
Table 1

Step-wise Multiple Linear Regression Analysis for the Prediction of Document Literacy From Year in School, GPA, Program of Study, and Learning Style (N=143)

\begin{tabular}{llllll}
\hline Variable & $\underline{B}$ & $\underline{\text { SE B }}$ & $\underline{\text { Beta }}$ & $\underline{\text { T }}$ & $\underline{\text { Sig T }}$ \\
\hline Step 1 & & & & \\
$\quad$ Year in School & 1.20 & .40 & .20 & 8.0 & .00 \\
GPA & 1.5 & .18 & .57 & 4.39 & .00 \\
(Constant) & 9.77 & 1.13 & & 8.67 & .00 \\
Step 2 & & & & \\
$\quad$ Learning style & -.01 & -.01 & .86 & -.17 & .87 \\
Prog of study & .08 & .10 & .89 & 1.18 & .24 \\
& & & & & \\
\hline
\end{tabular}

Note. $\mathrm{R}$ Square $=.44$ for step 1. An alpha level of .05 was used for all statistical tests.

\section{Table 2}

Step-wise Multiple Linear Regression Analysis for the Prediction of Quantitative Literacy From Year in School, GPA, Program of Study, and Learning Style (N=143)

\begin{tabular}{lrrrrr}
\hline Variable & $\underline{B}$ & $\underline{\text { SE B }}$ & $\underline{\text { Beta }}$ & $\underline{\text { Sig T }}$ \\
\hline Step 1 & & & & \\
$\quad$ Year in School & 1.90 & .43 & .33 & 7.98 & .00 \\
GPA & .98 & .19 & .38 & 4.39 & .00 \\
(Constant) & .68 & 1.20 & & .56 & .57 \\
Step 2 & & & & .17 & .99 \\
$\quad$ Learning style & .01 & .01 & .86 & 1.49 & .14 \\
Prog of study & .10 & .12 & .89 & & \\
\hline
\end{tabular}

Note. $\quad$ R Square $=.33$ for step 1 . An alpha level of .05 was used for all statistical tests. 
Table 3

Step-wise Multiple Linear Regression Analysis for the Prediction of Total Literacy From Year in School, GPA, Program of Study, and Learning Style $(\mathrm{N}=143)$

\begin{tabular}{lccccc}
\hline Variable & $\underline{B}$ & $\underline{\text { SE B }}$ & $\underline{\text { Beta }}$ & $\underline{\text { T }}$ & $\underline{\text { Sig T }}$ \\
\hline Step 1 & & & & \\
$\quad$ Year in School & 2.50 & .31 & .53 & 7.98 & .00 \\
GPA & 3.08 & .70 & .29 & 4.39 & .00 \\
(Constant) & 10.48 & 1.98 & & 5.28 & .00 \\
Step 2 & & & & & \\
$\quad$ Learning style & .00 & .00 & .86 & .02 & .99 \\
Prog of study & .099 & .13 & .89 & 1.56 & .12 \\
\end{tabular}

Note. R Square $=.45$ for step 1. An alpha level of .05 was used for all statistical tests.

Table 3 indicates that the predictor variables, year in school and GPA, were found to be significantly predictive of total literacy by the step-wise regression analysis. The combination of year in school with GPA accounted for 45 per cent of the explained variance in students' total literacy score. The magnitude of the $\mathrm{R}^{2}$ indicated that the predictor variables of year in school and GPA provided unique information about the criterion variable, total literacy, that was not provided by the other two variables in the equation. The significance of 0.00 for year in school and GPA, respectively, revealed a statistically significant predictive value for total literacy.

The total literacy score $\left(\mathrm{Y}_{\mathrm{k}}\right)$ was predicted by the regression equation: $\mathrm{Y}_{\mathrm{k}}=$ $10.48+.53$ (Year in school) +.29 (GPA). The size of the Sig $\mathrm{T}$ for the other two independent variables of learning style and program of study indicate that the additional variance explained by those variables were so negligible that they were not significant for predicting total literacy scores.

The hypothesis that learning style, GPA, year in school, and program of study, step-wise or collectively, did not significantly predict total literacy as measured by a total literacy score on the ADD when tested at the 0.05 level of significance was rejected.

\section{CONCLUSIONS}

The student's score for document literacy on the ADD was designed to measure the ability to locate, interpret, and process information that pertained to graphs, tables, and maps. Many of the examples used in the test were similar to those required in professional pilot and aerospace administration classes. Collectively and separately, GPA and year in school correlated positively with document literacy. The results suggested that students who persevered and who had a history of doing well in school performed better on the ADD. Although year in school and document literacy were positively correlated, the strength of the change in $\mathrm{R}^{2}$ suggested that year in school and GPA represented separate qualities. 
Years of formal education demonstrated the strongest main effect for performance of document literacy ability. This researcher concluded that the most likely explanation for improved performance of document literacy correlating with years of formal education was due to students' cumulative exposure to tables, graphs, and maps in aerospace technology department courses. Additionally, exposure to tables, graphs, and maps in other parts of the university curriculum could also have influenced students' improved ability in document literacy. Furthermore, year in school would likely measure such personal qualities as experience, maturity, and/or persistence.

The finding that GPA correlated positively with students' document literacy score on the ADD might be explained by the fact that GPA and document literacy measured many of the same traits that enabled students to do well in school-improved metacognitive strategies, testwiseness, more developed vocabulary and skill in reading, and more efficient/effective reading and study skills.

The fact that the findings associated with document literacy were echoed in the investigation of quantitative and total literacy may also be a matter of years of exposure and accumulated experience. Aerospace technology students at Indiana State University were required to take three quantitative gateway courses that emphasized quantitative skills used in aviation courses: physics, statistics, and algebra. Many students took these courses during their sophomore year or after. The fact that year in school correlated with quantitative literacy may have been explained by the fact that some students who were unable to pass those courses or who had difficulty with such courses had dropped out of the program altogether by their junior or senior year. Those that did poorly in the gateway courses but did not drop out of the aviation programs would have had additional exposure, since they would have had to repeat the courses to graduate.

This researcher also contends that the significant effects of GPA and year in school on quantitative literacy may also result from the fact that students who were skilled at inferential thinking tend to do well in both GPA and quantitative literacy. Quantitative literacy was defined as the knowledge and skills necessary to apply math operations, either singly or sequentially, to data embedded in printed tables and graphs. Underlying the ability to perform well in quantitative literacy is the ability to make inferences when some of the information provided was implicit. Kirsch and Mosenthal (1993) stated that students who were able to recognize and discern patterns tended to do well in school and in quantitative literacy. Because quantitative literacy required the respondent to compare features within and between documents and to detect patterns, this might account for the effect of GPA on quantitative and total literacy.

Because professional pilot students would tend to have more frequent exposure to aviation related graphs, tables, and maps in their aviation academic curricula it was expected that the professional pilot major would have higher scores than the aerospace administration major. However, program of study was not demonstrated to be a significant predictor of document, quantitative, or total literacy. One confounding problem with using program of study for a predictor variable in the aerospace technology department was the large number of students that changed their majors each year. Several of the freshman and sophomores who were uncertain of which program of study to pursue upon entering ISU changed their majors or ended up as double majors by their junior year. 
Other students changed their majors during their junior or senior year from professional pilot to aerospace administration due to the high cost of flight training.

Finally, this study attempted to investigate whether the skills of utilizing documents and quantitative reasoning were associated with individual learning styles. Although some research supports the notion of a significant correlation between learning styles and ability to perform well in certain academic areas over others, results of the study did not significantly support that relationship. There was no indication that any of the four specific individual learning styles enabled students to perform better in document, quantitative, or total literacy.

\section{RECOMMENDATIONS}

Although not fully explored in this investigation, the relationship of learning style with year in school and academic performance should be investigated. Data from the LTM in this study indicate that students categorized as having learning styles one and four were well represented in the freshman and sophomore groups but low in numbers in the junior and senior categories. Quilty attributes this attrition to possible "instructional selection bias" (Quilty, 1999, p. 11) and suggests that a longitudinal study might reveal whether students classified with particular learning styles were dropping out of aviation programs because of problems in academic performance or if, indeed, the students modified their learning styles in order to succeed in the aviation instructional setting.

The validity of the criterion variables investigated in this study, document, quantitative, and total literacy, also need further refinement and exploration. Document and quantitative literacy are complex constructs that pose enormous research difficulties. Venezsky (1992) argued that, "Document literacy is difficult to define empirically due to the limited amount of research done on it." Research on these variables in specific career areas is still scarce.

Aviation employers have expressed concern about the lack of math, critical thinking, and problem-solving skills of university graduates that are entering the aviation industry. An investigation of math skills, confidence in math ability, and academic performance of aviation students should be conducted. In the prologue to the ADD, students indicated their comfort level with math by selecting one of two choices: "I feel comfortable about doing most math problems" or "I feel uncomfortable about doing most math problems." Although the reliability of the wording of the question was not statistically tested, with 46 out of 143 aerospace technology students choosing the selection that conveyed that they felt uncomfortable with most math problems, further investigation into students' math skills, students' confidence in their own math abilities, and their subsequent academic performance seems warranted.

Because aviation management and professional pilot programs generally require competence in certain quantitative skills, further research into the relationship of success in the aviation programs, SAT math scores, and success in mathematics might also be warranted. Aviation students in general, are often required to take algebra, physics, calculus and statistics. Courses such as these can open the gates or block the way for students interested in technical careers. According to Seymour and Hewitt, each year about one third of the talented pool of freshmen who select engineering, science, and technical career programs requiring gateway math courses switch to other fields (Seymour and 
Hewitt, 1994, p. 37). Similar attrition rates are also common in many aviation programs; by their sophomore year, aviation students switch to other majors in disproportionately high numbers. The notion that students who leave such programs requiring quantitative skills are not cut out to be pilots or administrators in the technical field of aviation might be challenged. There may be a need to reexamine how aviation educators can successfully improve students' math deficiencies. 


\section{REFERENCES}

Armbruster, B. B., \& Gudbrandsen, B. (1986). Reading comprehension instruction in social studies programs. Reading Research Quarterly, 21(1), 36-48.

Barton, P. E. (1994). Becoming literate about literacy. Princeton, NJ: Educational

Testing Service. (Eric Document Reproduction Service No. ED 372 114)

Bloom, B. S. (1976). Human characteristics and school learning. New York: McGrawHill Book Company.

Chisman, F. (1990). Leadership for literacy. San Francisco: Jossey Bass publishers.

Dunn, R. \& Dunn, K. (1993). Teaching students through their individual learning styles. Boston: Allyn and Bacon.

General Aviation Manufacturers Association. (1975). Specification for pilot's operating handbook: GAMA specification No. 1. Washington, DC: General Aviation Manufacturers Association.

Goodlad, J. I. (1984). A place called school. New York: McGraw Hill.

Guthrie, J. T., \& Mosenthal, P. (1987). Literacy as multidimensional: Locating information and reading comprehension. Educational Psychologist, 22 (3 \& 4), 279-297.

Guthrie, J. T., Seifert, M., \& Kirsch, I. S. (1986). Effects of education, occupation, and setting on reading practices. American Educational Research Journal, 23(1), 151-160.

Head, J. T., \& Moore, D. M. (1991). The effects of graphic format and cognitive style on the immediate and delayed interpretation of complex quantitative data. Canadian Journal of Educational Communication, 20(1), 3-15.

Kirsch, I. S., \& Mosenthal, P. B. (1990). Exploring document literacy: Variables underlying the performance of young adults. Reading Research Quarterly, 25(1), 5-30.

Kirsch, I. S., \& Mosenthal, P. B. (1993). Integration strategies: Higher order thinking applied to documents. Journal of Reading, 36(4), 322-327.

Lawrence, B. H. (1988). Mathematical myths and adult learners. Cincinnati, Ohio: Paper presented at the conference "Teaching adults: Myths and realities." (Eric Document Reproduction Service No. ED 300 672)

McCarthy, B. (1995). Introduction to the 4MAT system: Teaching to learning styles with right/left mode techniques. Barrington, IL: EXCEL Inc.

McCarthy, B. (1996). About learning. Barrington, IL: EXCEL Inc.

McCarthy, B., \& St. Germain, C. (1996). The 4MAT research guide. Barrington, IL: EXCEL Inc.

Mikulecky, L. (1985). Literacy task analysis: defining and measuring occupational literacy demands. Chicago, IL: Paper presented at the National Adult Educational Research Association. (Eric Document Reproduction Service No. ED 262 206)

Miller, P. A. (1982). Reading documents in a high-technology industry. Journal of Reading, 26(2), 109-115.

Mosenthal, P. B., \& Kirsch, I. S. (1989). Lists: The building blocks of documents. Journal of Reading, 33(1), 58-60.

Mosenthal, P. B., \& Kirsch, I. S. (1993). Profiling students' quantitative strategy abilities. Journal of Reading, 36(8), 668-674.

Phillipi, J. W. (1988). Matching literacy to job training: Some applications from military programs. Journal of Reading, 31(7), 658-666. 
Quilty, S.M. (1996). Cognitive learning bias of university aviation students in an aviation program. Journal of Air Transportation World Wide (on-line journal), http://unomaha.edu/ himbergr/aviation.html.

Quilty, S. M. (1999). Analysis and comparison of cognitive learning preferences among airline pilots, corporate pilots, and aviation students. Journal of Air Transportation World Wide, 4(1), 1-13.

Seymour, E., \& Hewitt, N. M. (1994). Talking about leaving: Factors contributing to high attrition rates among science, mathematics, and engineering undergraduate majors. Final report to the Alfred Sloan Foundation. Boulder: University of Colorado Bureau of Sociological Research.

Sheehan, K. M., \& Mislevy, R. (1990). Integrating cognitive and psychometric models to measure document literacy. Journal of Educational Measurement, 27(3), 255-272.

Sternberg, R. J. (1990). Intellectual styles: Theory and classroom implications. In R. McClure (Ed.), Learning and thinking styles: Classroom interaction (pp. 18-42). Washington, DC: National Education Association.

St. Germain, C. (1996). The Learning Type Measure (LTM) manual. Barrington, IL: EXCEL, Inc.

St. Germain, C., Lieberman, M, \& Cohen, M. (1995). Reliability and validity study of the Learning Type Measure (LTM). Barrington, IL: EXCEL, Inc.

Sticht, T. G., \& Armstrong, W. B. (1994). Adult literacy in the United States: A compendium of quantitative data and interpretive comments. San Diego, CA: San Diego Community College District.

Taba, H. (1962). Curriculum development: Theory and practice. New York: Harcourt, Brace, and World, Inc.

Taylor, R. (1991). Aircraft performance: The forces without. Greewich, CT: Belvoir Publications. Press.

Tufte, E. (1986). The visual display of quantitative information. Cheshire, CT: Graphics

Venezky, R. L. (1992). Matching literacy testing with social policy: What are the alternatives? Philadelphia, PA: University of Pennsylvania, National Center on Adult Literacy. 